\title{
Erratum
}

\section{Erratum to: Mathematical analysis of whispering gallery modes in graded index optical micro-disk resonators ${ }^{\star}$}

Eur. Phys. J. D (2020) 74: 221, https://doi.org/10.1140/epjd/e2020-10303-5

Stéphane Balac ${ }^{1, a}$, Monique Dauge ${ }^{1}$, Yannick Dumeige ${ }^{2}$, Patrice Féron $^{2}$, and Zoïs Moitier ${ }^{3}$

${ }^{1}$ UNIV. RENNES, CNRS, IRMAR - UMR 6625, 35000 Rennes, France

2 UNIV. RENNES, CNRS, FOTON-UMR 6082, Enssat, 22305 Lannion, France

${ }^{3}$ Department of Applied Mathematics, University of California, Merced, 5200 North Lake Road, Merced, CA 95343, USA

Received 17 November 2020 / Accepted 17 November 2020

Published online 8 December 2020

(C) EDP Sciences / Società Italiana di Fisica / Springer-Verlag GmbH Germany, part of Springer Nature, 2020

The affiliations for the article are corrected.

Instead of:

Stéphane Balac ${ }^{1, a}$, Monique Dauge ${ }^{1}$,

Yannick Dumeige ${ }^{2}$, Patrice Féron ${ }^{2}$, and Zoïs Moitier ${ }^{1}$

1 Department of Applied Mathematics, University of California, Merced, 5200 North Lake Road, Merced, CA 95343, USA

${ }^{2}$ UNIV. RENNES, CNRS, FOTON-UMR 6082, Enssat, 22305 Lannion, France it should be:

Stéphane Balac ${ }^{1, a}$, Monique Dauge ${ }^{1}$,

Yannick Dumeige $^{2}$, Patrice Féron ${ }^{2}$, and Zoïs Moitier ${ }^{3}$

${ }^{1}$ UNIV. RENNES, CNRS, IRMAR-UMR 6625, 35000 Rennes, France

${ }^{2}$ UNIV. RENNES, CNRS, FOTON-UMR 6082, Enssat, 22305 Lannion, France

3 Department of Applied Mathematics, University of California, Merced, 5200 North Lake Road, Merced, CA 95343, USA

${ }^{\star}$ The online version of the article can be found at https://doi.org/10.1140/epjd/e2020-10303-5.

a e-mail: stephane.balac@univ-rennes1.fr 